\title{
Correlation between Different Parameters of Disease Status and Quality of Life in Patients with Ankylosing Spondyolitis
}

\author{
A.Y.Ali, R.M.ElTanawy, R.M.Fawzy and E.M.Abdel bary \\ Rheumatology Dept.,Faculty of Medicine, Benha Univ., Benha, Egypt \\ E-Mail:Ehabelbary@gmail.com
}

\begin{abstract}
Ankylosing spondylitis (as) is a complex, conceivably incapacitating illness that is treacherous in beginning, advancing to radiological sacroiliitis more than quite a while. The point of this examination was to research the connection between sickness status and personal satisfaction (qol) in ankylosing spondylitis patients. A sum of 20 as male patients analyzed by.. Were remembered for this investigation. Patients' illness status was evaluated utilizing; the shower as sickness action list (basdai), the shower as useful record (basfi), the shower as metrology file (basmi), the maastricht as enthesitis score (mases), as personal satisfaction (asqol), multidimensional appraisal of weakness (maf). The mean asqol score in patients was altogether higher $(\mathrm{p}=0.001)$ contrasted with the control. Patients with fringe joint pain had higher asqol score than patients without with genuinely huge difference $(\mathrm{p}=0.002)$. Statically critical positive relationships between's bas (qol) score and basdai, basfi, maf, mases, basmi scores ( $\mathrm{p}=0.001,0.003,0.004,0.002,0.000$ separately). Similar to a persistent incendiary sickness that influences hrqol particularly with higher infection action, useful handicap, and with more fringe joint association. Accordingly it is essential to improve infection status to accomplish better qol.
\end{abstract}

Keywords: Ankylosing spondylitis, Fatigue, Quality of life, Disease activity parameters.

\section{Introduction}

Ankylosing spondylitis (AS) is a persistent provocative sickness that typically influences the sacroiliac joints in the beginning phases and may include the pivotal skeleton at later stages [1].

Torment and solidness have been depicted as significant essential manifestations of AS, while weariness has as of late been presented as a significant indication altogether affecting patient's personal satisfaction (QoL) [2].

Enthesitis, a general sign of spondyloarthritides, is aggravation of the cause and inclusion of tendons, ligaments, aponeuroses, annulus fibrosis, joint containers and sash. Enthesitis has been viewed as the underlying site of irritation in SA, which just later stretches out to compared synovial tissues [3].

Aspiratory association is a known sign in patients with ankylosing spondylitis (AS), arising either as interstitial lung illness or as prohibitive pneumonic capacity [4].

These clinical manifestations and ensuing illness movement bring about generous utilitarian limits and impedance of wellbeing related personal satisfaction (HRQoL) [5]. There is a developing interest in QoL evaluations and the utilization of patient-detailed result (PRO)measures in persistent crippling illnesses. These boundaries have gotten progressively valuable to assess the adequacy of new treatment methodologies, particularly the counter tumor rot factor (TNF) specialists. Given the effect of AS on HRQoL spaces, particularly torment, actual working, weakness and mental well-being [6].

\section{Aim of the work}

The aim of this study was to investigate the relationship between disease status and quality of life (QoL)in a serious of ankylosing spondylitis patients.

\section{Patients and methods}

This study was led on twenty Ankylosing Spondylitis
(AS) patients gathered from those going to the Inpatient's Unit and Outpatient's Clinic of Rheumatology, Rehabilitation and actual medication of Benha University Hospitals and Outpatient's Clinic of Rheumatology and Rehabilitation of Agouza Military Hospital. Analysis was made by the Modified New York measures for arrangement of AS [7]. Twenty clearly solid volunteers were likewise included as a benchmark group.

A verbal assent was taken from all patients and control subjects preceding support in the examination that was affirmed by the moral panel of the personnel of Medicine, Benha University.

Patients under 16 years of age, those with other musculoskeletal issues in the spine or thoracic enclosure, cardiopulmonary infection, a simultaneous ailment that could be sensibly expected to influence the patient's practical level or QOL were avoided from the investigation.

Age and illness span of the patients were recorded. The patients were surveyed utilizing Arabic variants of Bath AS Disease Activity Index (BASDAI) [8], Arabic form of Bath AS Functional Index (BASFI) [9], weakness was evaluated utilizing multi dimensional appraisal of weariness (MAF) [10], Bath AS Metrology Index (BASMI) [11] and Maastricht AS Enthesitis Score (MASES) [12] were assessed.

Appraisal of AS Quality Of Life by (ASQol) [13]. It comprises 18 things and every thing was scored as $(1=$ yes $)$ or $(0=$ no). A score of ( 1$)$ shows poor QoL. All out scores range from 0 to18, with a higher score demonstrating low quality of life.

Radiological Investigations: All patients were exposed to cervical, chest, thoracic lumbosacral, pelvic X-beam radiographies.

Measurable investigation: All information were exposed to update and approval then depiction and examination on IBM-viable PC by utilizing SPSS (Statistical Package for the Social Science) program 
variant 23.0.0, Microsoft Office Excel 2007, and GraphPad Prism 6. Clear insights were performed for all considered boundaries in the three contemplated gatherings and were introduced as mean, middle, standard deviation (SD), least, greatest, reach, and rates.

The examination between bunches in regards to subjective information was finished by utilizing Chisquare test; while the correlation between two gatherings with quantitative information and parametric circulation were finished by utilizing Independent t-test.

The degree of importance was determined by the accompanying likelihood $(\mathrm{P})$ values: $\mathrm{P}>0.05=$ no critical (NS), $\mathrm{P}<0.05=$ huge $(\mathrm{S}), \mathrm{P}<0.001=$ highly significant (HS).

\section{Results}

This study included 20 male ankylosing spondylitis patients (AS) patients. Their ages ranged between 28-43 years with a mean \pm SD of $35.1 \pm 4.39$ years; A group of 20 age matched male volunteers were also included as a control group. Their ages ranged between 25-41 years with a mean \pm SD of $36.4 \pm 5.09$ years. This study showed there were no statistically significant differences between the two groups regarding age, and $\mathrm{BMI}(\mathrm{P}=0.34$ and 0.24 respectively).

Regarding BASDAI score; 8 (40\%) patients had BASDAI $\geq 4$ and the remaining $12(60 \%)$ patients had score $<4$.

Family history of spondylarthritis was present in 6 $(30 \%)$ patients.

The lumbar spine was the most commonly affected in AS patients $(70 \%)$ compared to the dorsal $(10 \%)$ and the cervical spine (15\%). Sacroiliac joints were involved unilaterally in 7 (35\%) patients and bilaterally in $13(65 \%)$ patients. Regarding X- ray grading: it was graded $1 \backslash 2 \backslash 3 \backslash 4$ in $6(30 \%) \backslash 8(40 \%) \backslash 4(20) \backslash 2(10 \%)$ patients respectively.

Table (1) Comparison between the studied groups regarding BAS Quality Of Life by BAS (QoL), Multi-dimensional assessment of fatigue (MAF) scores.

\begin{tabular}{|c|c|c|c|c|}
\hline Variable & $\begin{array}{c}\text { Patients Group } \\
\text { No. }=20\end{array}$ & $\begin{array}{c}\text { Control Group } \\
\text { No. }=20\end{array}$ & Test value• & P-value \\
\hline $\begin{array}{l}\text { MAF } \\
\text { Mean } \pm \text { SD }\end{array}$ & $33.55 \pm 6.46$ & $7.3 \pm 2.9$ & -8.871 & 0.001 \\
\hline $\begin{array}{l}\text { AS QoL } \\
\text { Mean } \pm \text { SD }\end{array}$ & $13.1 \pm 2.45$ & $4.5 \pm 1.68$ & -7.725 & 0.001 \\
\hline
\end{tabular}

Highly significant differences were reported between the studied groups regarding MAF and BAS (QoL) scores (P=0.001).

Table (2) Comparison between patients with peripheral arthritis and those without peripheral arthritis regarding BAS Quality Of Life by BAS (QoL).

\begin{tabular}{lccc}
\hline Variable & Patients with peripheral arthritis & Patients without peripheral arthritis & P value \\
\hline BAS (QoL) & $14.2 \pm 1.2$ & $8.3 \pm 2.1$ & $<0.002$ \\
\hline
\end{tabular}

Patients with peripheral arthritis had higher BASQoL score than those without peripheral arthritis with statistically significant difference $(\mathrm{p}<0.002)$.

Table (3) Correlation between Score Of BAS (QoL) with Age, and BMI.

\begin{tabular}{lcc}
\hline \multirow{2}{*}{ Variable } & \multicolumn{2}{c}{ Score of BAS $($ QoL) } \\
\cline { 2 - 3 } & $\mathbf{R}$ & P-value \\
\hline Age & 0.022 & 0.89 \\
BMI & 0.21 & 0.43 \\
\hline
\end{tabular}

The Previous table shows that there was statically insignificant positive correlations between Score of BAS (QoL) with age and BMI ( $\mathrm{p}=0.89,0.02$ respectively).

Table (4) Correlation between BAS (QoL) Score with different disease scores.

\begin{tabular}{lcc}
\hline \multirow{2}{*}{ Variable } & \multicolumn{2}{c}{ Score of BAS $($ QoL) } \\
\cline { 2 - 3 } & $\mathbf{R}$ & P-value \\
\hline BASDAI & 0.84 & 0.001 \\
BASFI & 0.79 & 0.003 \\
MAF & 0.90 & 0.004 \\
MASES & 0.87 & 0.002 \\
BASMI & 0.90 & 0.000 \\
\hline
\end{tabular}


BASDAI Bath ankylosing spondylitis disease activity index, BASFI: Bath ankylosing spondylitis Functional Index, MAF: multidimensional assessment of fatigue, BASMI Bath ankylosing spondylitis metrology index, MASES: Maastricht AS Enthesitis Score.
The Previous table showed that there was statically significant positive correlations between BAS (QoL) score and BASDAI, BASFI, MAF, MASES, BASMI scores $(\mathrm{P}=0.001,0.003,0.004,0.002,0.000$ respectively).

Table (5) Relation between BAS (QoL) Score and radiological grading among AS patients.

\begin{tabular}{lccc}
\hline Drug & N & BAS $($ QoL) Mean \pm SD & P \\
\hline Grade I & 6 & $4.3 \pm 2.1$ & $<0.01$ \\
Grade II & 5 & $6.2 \pm 1.2$ & \\
Grade III & 7 & $8.2 \pm 1.1$ & \\
Grade IV & 2 & $14.1 \pm 0.9$ & \\
\hline
\end{tabular}

SD: Standard deviation Bold values are significant at $\mathrm{p}<0.05$.

This table shows higher BAS (QoL) score with higher $\mathrm{x}$-ray score of sacroiliac joints $(\mathrm{p}=0.01)$.

\section{Discussion}

Identification of the elements that are related with poor HRQoL among AS patients and revision of the modifiable variables can be of foremost significance for creating powerful administration procedures in these patients [14].

The current investigation uncovered that AS patients had fundamentally higher ASQoL score than the controls connoting that AS cases experience the ill effects of poor QoL. In concurrence with this result, some past investigations utilizing diverse QoL polls among patients with and AS detailed similar discoveries. For example, [15] found that AS patients had a critical lessening in complete scores of the nonexclusive instrument SF-36 for assessment of HRQoL and in its spaces contrasted with the coordinated controls. [16],[17] used SF-36 scores and uncovered that AS cases had worseer score than the controls. Similarly,[18] estimated the HRQoL in AS patients and discovered that all critical components of wellbeing are fundamentally impeded by AS. Strangely, a meta-investigation by [19] announced that the effect of AS on QoL is more noteworthy than type II diabetes mellitus, and like rheumatoid joint pain. Subsequently, such discoveries underline on the meaning of HRQoL in the treatment of AS cases.

Fringe contribution predicts more forceful illness especially when early-sickness course happens [24]. In the current examination, Patients with fringe joint inflammation experienced higher BASQoL score than those without fringe joint inflammation with critical contrast $(\mathrm{p}<0.002)$. Likewise, higher BAS (QoL) score was seen with higher $\mathrm{x}$-beam score of sacroiliac joints $(p=0.01)$. [21],[14] revealed poor QoL in AS patients was fundamentally connected with more serious radiological changes, as demonstrated by extreme kyphosis [21].

It is viewed as that patients with high infection movement and more awful useful status had fundamentally less fortunate QoL scores. The current investigation announced critical positive connection between's the action score and the ASQoL. In [14] study; ASQoL altogether connected with boundaries of illness movement including VAS-morning firmness, VAS-weakness, VAS-night agony, BASDAI and ASDAS which is likewise in concurrence with [16],[20]. Despite the fact that, Others recorded converse relationship among BASDAI and most of the SF-36 spaces and with the all out score [21], [22].

Turan et al. [23] revealed that the personal satisfaction of patients with AS were generally related with enthesis inclusion in their investigation which was in concurrence with the current examination where we assessed enthesitis by MASES.

All in all: AS is a constant provocative infection that influences HRQoL particularly with higher sickness movement, practical inability, and with more fringe joint inclusion. Along these lines it is imperative to improve infection status to achieve better QoL.

\section{References}

[1] M.Ghasemi-Rad, H.Attaya, E.Lesha. Ankylosing spondylitis: A state of the art factual backbone. World J Radiol, Vol.7 (9), PP.236-252,2015.

[2] Q.Guo, Y.Wang, D.Xu. Rheumatoid arthritis: pathological mechanisms and modern pharmacologic therapies. Bone Res, Vol.6(1), PP.1-15,2018.

[3] A.S.Kehl, M.Corr, M.H.Weisman. Review: Enthesitis: New Insights Into Pathogenesis, Diagnostic Modalities, and Treatment. Arthritis Rheumatol, Vol.68(2), PP.312-322,2016.

[4] M.Momeni, N.Taylor, M.Tehrani. Cardiopulmonary manifestations of ankylosing spondylitis. Int $\mathrm{J}$ Rheumatol, Vol.2011, PP.728471.2011

[5] H.Bodur,S.Ataman,L.Akbulut.Characteristics and medical management of patients with rheumatoid arthritis and ankylosing spondylitis. Clinical Rheumatology, Vol. 27, PP.1119-1125,2008.

[6] E.E.Bostan, P.Borman, H.Bodur. Functional disability and quality of life in patients with ankylosing spondylitis. Rheumatology International.vol,23, PP.121-126,2003.

[7] Akgul O, Ozgocmen S. Classification criteria for spondyloarthropathies. World Journal of Orthopedics. 2011; 2(12): 107.

[8] Y.El Miedany, S.Youssef, A.Mehanna. Defining disease status in ankylosing spondylitis: validation and crosscultural adaptation of the Arabic bath ankylosing 
spondylitis functional index (BASFI), the bath ankylosing spondylitis disease activity index (BASDAI), and the bath ankylosing spondylitis global score (BASG). Clinical rheumatology, Vol.27(5), PP.605-612,2008.

[9] S.Rostom, K.Benbouaaza, B.Amine. Psychometric evaluation of the Moroccan version of the Bath Ankylosing Spondylitis Functional Index (BASFI) and Bath Ankylosing Spondylitis Disease Activity Index (BASDAI) for use in patients with ankylosing spondylitis. Clinical rheumatology, Vol.29(7), PP.781-788,2010.

[10] S.Hewlett, E.Dures, C.Almeida. Measures of fatigue: Bristol rheumatoid arthritis fatigue multidimensional questionnaire (braf mdq), bristol rheumatoid arthritis fatigue numerical rating scales (braf nrs) for severity, effect, and coping, chalder fatigue questionnaire (cfq), checklist individual strength (cis20r and cis8r), fatigue severity scale (fss), functional assessment chronic illness therapy (fatigue)(facitf), multidimensional assessment of fatigue (maf), multi dimensional fatigue inventory (mfi), pediatric quality of life.... Arthritis care \& research. , Vol.63(S11), PP.S263-S286, 2011.

[11] P.J.Mease. Measures of psoriatic arthritis: Tender and Swollen Joint Assessment, Psoriasis Area and Severity Index (PASI), Nail Psoriasis Severity Index (NAPSI), Modified Nail Psoriasis Severity Index (mNAPSI), Mander/Newcastle Enthesitis Index (MEI), Leeds Enthesitis Index (LEI), Spondyloarthritis Research Consortium of Canada (SPARCC), Maastricht Ankylosing Spondylitis Enthesis Score (MASES), Leeds Dactylitis Index (LDI), Patient Global for Psoriatic Arthritis, Dermatology Life Quality Index (DLQI), Psoriatic.... Arthritis Care \& Research, Vol. 63(S11), PP.S64S85,2011.

[12] D.van der Heijde, R.Landewé, E.Feldtkeller. Proposal of a linear definition of the Bath Ankylosing Spondylitis Metrology Index (BASMI) and comparison with the 2-step and 10-step definitions. Annals of the rheumatic diseases, Vol.67(4), PP.489493,2008.

[13] M.T.Duruöz, L.Doward, Y.Turan. Translation and validation of the Turkish version of the Ankylosing Spondylitis Quality of Life (ASQOL) questionnaire. Rheumatology international, Vol. 33(11), PP.2717$2722,2013$.

[14] R.A.Sallam, A.S.Elbahnasawy. Health related quality of life (HRQoL) in ankylosing spondylitis patients: Relation to clinical features, disease activity and radiographic damage. The Egyptian Rheumatologist, Vol. 42(4), PP.287-290,2020.

[15] L.Law, J.B.Rehnman, A.Deminger. Factors related to health-related quality of life in ankylosing spondylitis, overall and stratified by sex. Arthritis research \& therapy, Vol. 20(1), PP.284,2018.

[16] F.Salaffi, M.Carotti, S.Gasparini. The health-related quality of life in rheumatoid arthritis, ankylosing spondylitis, and psoriatic arthritis: a comparison with a selected sample of healthy people. Health and quality of life outcomes, Vol.7(1), PP.25,2009.

[17] J.C.Davis, D.van der Heijde, M.Dougados. Reductions in health-related quality of life in patients with ankylosing spondylitis and improvements with etanercept therapy. Arthritis Care \& Research: Official Journal of the American College of Rheumatology. 2005; 53(4): 494-501.

[18] H.Dagfinrud, A.M.Mengshoel, K.B.Hagen. Health status of patients with ankylosing spondylitis: a comparison with the general population. Annals of the Rheumatic Diseases, Vol. 63(12), PP.1605$10,2004$.

[19] X.Yang, D.Fan, Q.Xia. The health-related quality of life of ankylosing spondylitis patients assessed by SF-36: a systematic review and meta-analysis. Quality of Life Research, Vol.25(11), PP.271123,2016.

[20] Ö.Yılmaz, A.Tutoğlu, Y.Garip. Health-related quality of life in Turkish patients with ankylosing spondylitis: impact of peripheral involvement on quality of life in terms of disease activity, functional status, severity of pain, and social and emotional functioning. Rheumatology international, Vol. 33(5), PP.1159-63,2013.

[21] O.Özdemir. Quality of life in patients with ankylosing spondylitis: relationships with spinal mobility, disease activity and functional status. Rheumatol Int, Vol. 31(5), PP. 605-610. 2011

[22] J.C.Huang, B.P.Qian, Y.Qiu. Quality of life and correlation with clinical and radiographic variables in patients with ankylosing spondylitis: a retrospective case series study. BMC musculoskeletal disorders, Vol. 18(1), PP.352,2017.

[23] Y.Turan, M.T.Duruöz, L.Cerrahoglu. Quality of life in patients with 35. ankylosing spondylitis: a pilot study. Rheumatol Int, Vol.27(10), PP.895-899,2007.

[24] L.Gensler. Clinical features of ankylosing spondylitis. In: Rheumatology. Hochberg MC, Silman AJ, Smolen JS, Weinblatt ME, Weisman MH (eds) 5th edn. Mosby Elsevier, Philadelphia, Vol.15, PP.1129-34,2001. 